Atualidades de Pesquisa

\title{
FUNÇÃO DO SEMELHANTE COMO FUNDAMENTO DO TRABALHO COM AS CRIANÇAS EM GRUPOS: UMA CONTRIBUIÇÃO PARA OS ESTUDOS SOBRE O DESENVOLVIMENTO PSÍQUICO
}

Tese de Doutorado no Instituto de Psicologia da Universidade de São Paulo

\author{
Autora \\ Carolina Cardoso Tiussi \\ Orientadora \\ Profa. Dra. Maria Cristina Machado Kupfer \\ (Universidade de São Paulo)
}

Banca examinadora

Profa. Dra. Leda Mariza Fischer Bernardino (Associação Psicanalítica de Curitiba), Prof. Dr. Daniel Revah (Universidade Federal de São Paulo), Profa. Dra. Emilia Estivalet Broide (Associação Psicanalítica de Porto Alegre), Prof. Dr. Pablo de Carvalho Godoy Castanho (Universidade de São Paulo) 
A função do semelhante, investigada nessa tese, diz respeito à relação horizontal entre as crianças e suas especificidades, ou seja, o que somente uma criança poderia fazer por outra. Iniciamos com um levantamento sobre o campo grupal, que é o dispositivo clínico utilizado como campo da pesquisa. Em seguida, discutimos os grupos heterogêneos em Educação Terapêutica. São grupos compostos por crianças com diferentes questões subjetivas, aumentando a diversidade e as possibilidades de encontros inéditos entre elas. Após, realizamos um levantamento sobre o semelhante nas obras de Sigmund Freud, Jacques Lacan e René Kaës. Esse levantamento, em conjunto com três vinhetas que analisamos, permitiu uma caracterização da função do semelhante. Com isso, queremos sustentar a tese de que, nos grupos heterogêneos, a função do semelhante seria um operador de leitura norteador do trabalho da coordenação. Verificamos que do encontro com o semelhante pode surgir um espaço para a alteridade. 